\title{
Characterization of cavities in carcerands
}

\author{
Heung-Jin Choi, Donald J. Cram, Carolyn B. Knobler and Emily F. Maverick* \\ Department of Chemistry and Biochemistry, University of California, Los Angeles, \\ CA $90024-1569$
}

\begin{abstract}
Carcerands are 'closed-surface, globe-shaped compounds with enforced hollow interiors' (ref. 1) that imprison template molecules during shell closure. Hemicarcerands possess holes in their shells which, while they do not prevent the isolation and characterization of complexes ('hemicarceplexes'), do allow entry and departure of guests (ref. 2). Space-filling models have guided the design of these molecules, and a number of the designs have been confirmed by X-ray crystal structure analysis. However, the nature of the host-guest interaction is seldom established by the crystal structure, presumably because of thermal or static disorder of the guest and/or external solvent molecules.

While the presence of the guest, and its motional state, can be determined by other methods, the size and shape of the cavity and its relationship to the guest may be more completely described by the molecular models or the related, more quantitative, atomatom potentials (ref. 3). Potential-energy studies require atomic positions from crystal structures or from molecular mechanics. In this paper we explore the cavities of three hemicarceplexes, and compare and contrast their host-guest interactions with those in 'velcraplexes' (ref. 4).

'Velcrands' do not encapsulate guests but instead form four-fold, lock-key dimers ('velcraplexes'), with large surfaces of contact between monomers. In the present dimers, the keys and locks are, respectively, methyl groups and corresponding holes that serve to position and hold the monomers in place. Both homo- and hetero-dimers may be formed, with a wide range of intra-complex non-bonded contacts and corresponding free energies of binding.
\end{abstract}

\section{INTRODUCTION}

In this paper we describe three hemicarceplexes and three velcraplexes with especial reference to the complementarity of the complexing partners. The molecular coordinates of the molecules presented here come from crystal studies which are fraught with crystallographic problems. All crystals must be mounted in capillaries, all contain many solvent molecules, usually disordered, and all structures are underdetermined. Our goal is to combine the methods of X-ray crystallography, molecular modeling and potential energy calculations to analyze and refine the models, and to correlate the solid-state structural results with phenomena in solution. We test here the molecular free surface area as a probe of host-guest interactions.

\section{FREE SURFACE AREA}

To estimate this quantity (ref. 3), the surface area of atom 1, determined by its van der Waals radius, is marked off in grid points. At each grid point the atoms list is scanned. If the surface of another atom, atom 2 , is within a distance $r_{\text {incr }}$ of that point, then the point is considered 'occupied'. It is clear that only a few intermolecular contacts can be equal to the sum of the van der Waals radii; a somewhat longer 'contact' will exclude solvent molecules and also indicate a strong attractive force. The $r_{\text {incr }}$ value used here is $0.2 \AA$. The 'free surface area' of an atom is equal to $f \cdot A$, where $f=$ (unoccupied grid points/total grid points), and $A$ is the total area. The free surface area of the molecule is the sum of the free surface areas of the individual atoms. Crystal coordinates are used; $\mathrm{H}$ atoms are included in calculated positions $(\mathrm{C}-\mathrm{H}=1.08 \AA$ ). 


\section{THREE HEMICARCEPLEXES}

Carcerands are 'closed' in templating solvents. Carcerands imprison their guest solvent molecules, while hemicarcerands are able to release or replace the contents of their cavities through various mechanisms. One may view these molecules as globes, made up of bowl-shaped northern and southern hemispheres, with bridging groups as spacers spanning the equator. Thus the interior space of the globe can be designed for a specific range of sizes and shapes of guests. The first example, 1, a globular molecule with [1.1.1] orthocyclophane units at the polar caps and three $-\mathrm{CH}_{2} \mathrm{C} \equiv \mathrm{CC} \equiv \mathrm{CCH}_{2}$ - groups forming slanted bridges that cross the equator, was prepared in pyridine, and crystallized from $\mathrm{CH}_{2} \mathrm{Cl}_{2}$ (ref. 5).
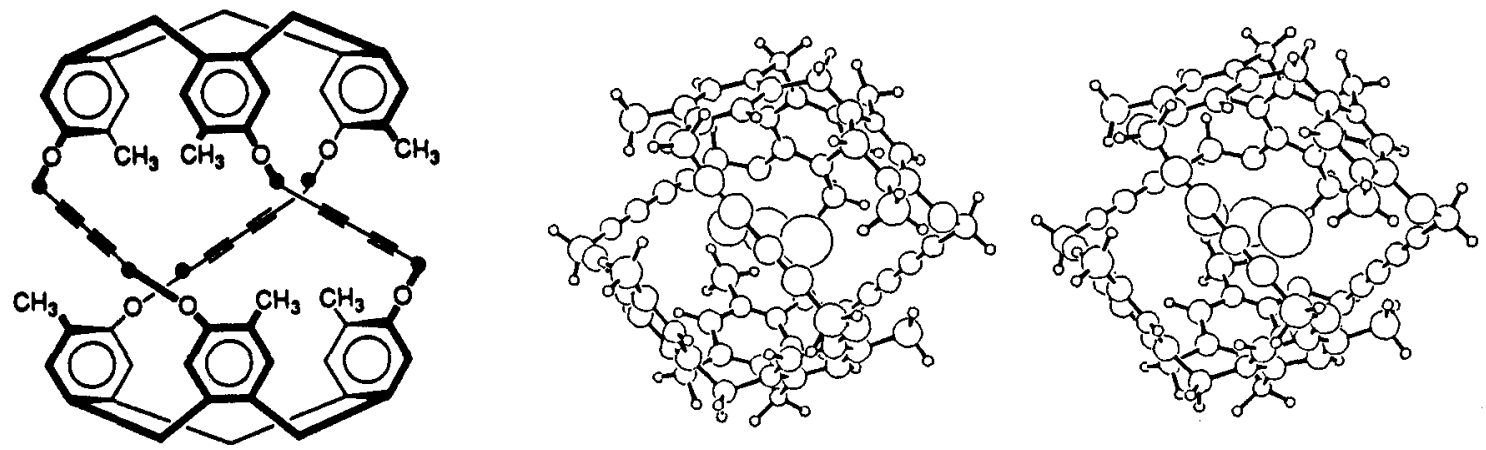

Fig. 1. Stereoview of 1 with $\mathrm{H}$ atoms and with unidentified guest (large spheres).

Elemental analysis gave $1 \cdot \mathrm{CH}_{2} \mathrm{Cl}_{2}$. The guest may be replaced in solution by $\mathrm{C}_{6} \mathrm{H}_{5} \mathrm{CH}_{3}, \mathrm{CH}_{3} \mathrm{CN}$, and a variety of other molecules; the host evidently accommodates them and allows them to enter and leave the cavity by adapting its conformation (ref. 5). In the crystal structure the portals are nearly closed by the rotation of one polar cap with respect to the other. The guest is very poorly characterized as a vague fouratom shape. Perhaps different molecules are encapsulated by hosts at different positions in the crystal, or perhaps all host molecules contain the same guest, but the guest's loose binding allows it to occupy different positions.

The compact, globular shape of the molecule gives it a relatively small surface area per unit volume, $1.06 \AA^{-1}$ (ref. 3 ; see below). The interior surface is reduced by $3 \AA^{2}$ by contacts with the guest at the van der Waals radius $+0.2 \AA$ level. (We use the abbreviation ' $v d W+0.2^{\prime}$ hereafter.) The poorly-described guest barely contacts several aromatic carbon atoms and one of the bridges. An attempt will be made to fit a disordered $\mathrm{CH}_{2} \mathrm{Cl}_{2}$ molecule to the electron density.

Hemicarceplex 2 was designed to possess a wide portal for ingress and egress of guests. It was templated around $\left(\mathrm{CH}_{3}\right)_{2} \mathrm{NCHO}$ (other amides and $\left(\mathrm{CH}_{3}\right)_{2} \mathrm{SO}$ also enable closure) (refs. 2, 6). Unusual chemistry, such as the preparation of cyclobutadiene from $\alpha$-pyrone, has been performed in its interior (ref. $6 \mathrm{~b}$ ). The host is a globe; 'bowls' comprising the northern and southern hemispheres are joined by three $-\mathrm{O}-\mathrm{CH}_{2}-\mathrm{O}$ bridges at the equator. $\mathrm{C}_{6} \mathrm{H}_{5} \mathrm{CH}_{2} \mathrm{CH}_{2}$ - 'feet' were added to the polar caps to increase the solubility of the host.
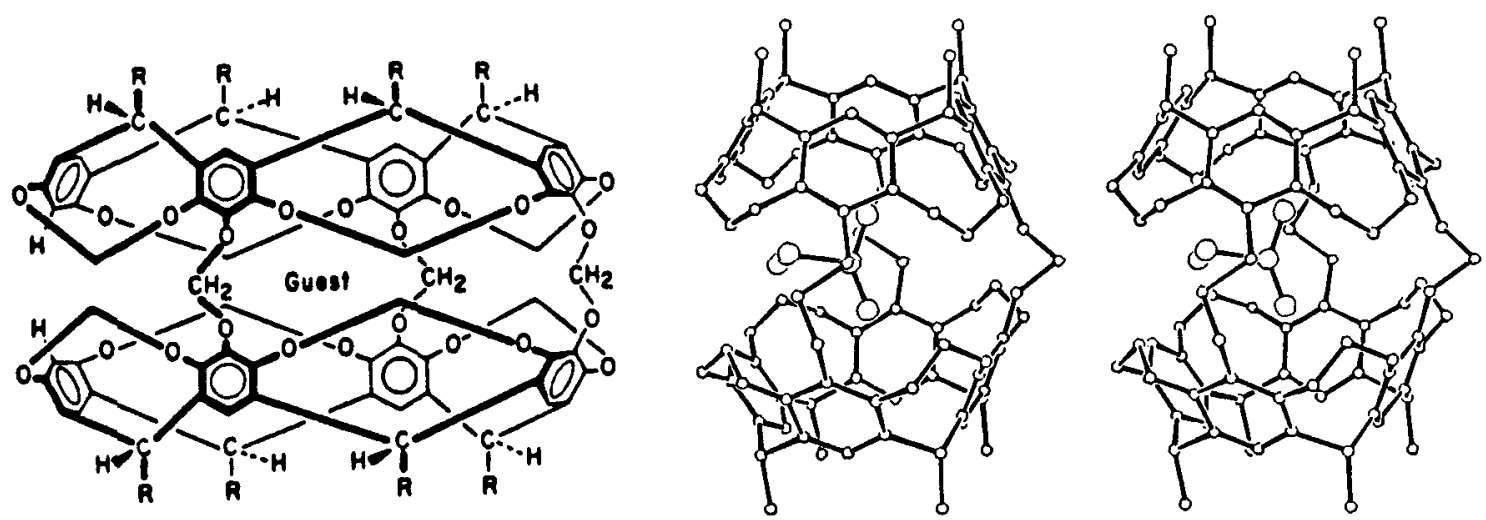

Fig. 2. Stereoview of 2 with incarcerated $\left(\mathrm{CH}_{3}\right)_{2} \mathrm{NCHO}$. Hydrogen atoms have been omitted, and the solubilizing $\mathrm{C}_{6} \mathrm{H}_{5} \mathrm{CH}_{2} \mathrm{CH}_{2}$ - 'feet' have been replaced by $-\mathrm{CH}_{3}$ groups, for clarity. 
The molecule in the crystal sits on a 2-fold axis and the $\left(\mathrm{CH}_{3}\right)_{2} \mathrm{NCHO}$ is therefore disordered; however, only one of the two positions of the guest may be present at any one time. It is not clear if the two possible positions are equally occupied; the positions obtained are distorted by the required symmetry. Host-guest contacts are reasonable. The interior surface area $(\mathrm{vdW}+0.2)$ is reduced by $14 \AA^{2}$ by these contacts. The $\mathrm{O}$ atom of the guest is near to methylene $\mathrm{H}$ atoms of the rims of the 'bowls'. Though the guest from the crystal study looks plausible, some bonded and non-bonded distances are short, and the model can be improved by constraining the guest to ideal geometry and by further exploration of the potential energy surface. In solution, $\left(\mathrm{CH}_{3}\right)_{2} \mathrm{NCHO}$ is rotating rapidly about all axes on the NMR time scale.

Ferrocene is beautifully incarcerated by host 3 (ref. 6a). The 'bowls' are the same as those in 2 , the 'feet' that enable solution chemistry are dangling $-\mathrm{CH}_{2} \mathrm{CH}_{2} \mathrm{CH}_{2} \mathrm{CH}_{2} \mathrm{CH}_{3}$ groups, and the four equator-spanning bridges are $m-\mathrm{CH}=\mathrm{N}-\mathrm{C}_{6} \mathrm{H} 4-\mathrm{N}=\mathrm{CH}$ - groups; thus the host is an octaimine. The configuration of the bridges provides wide portals and a high degree of preorganization for the complexation of relatively large guests.
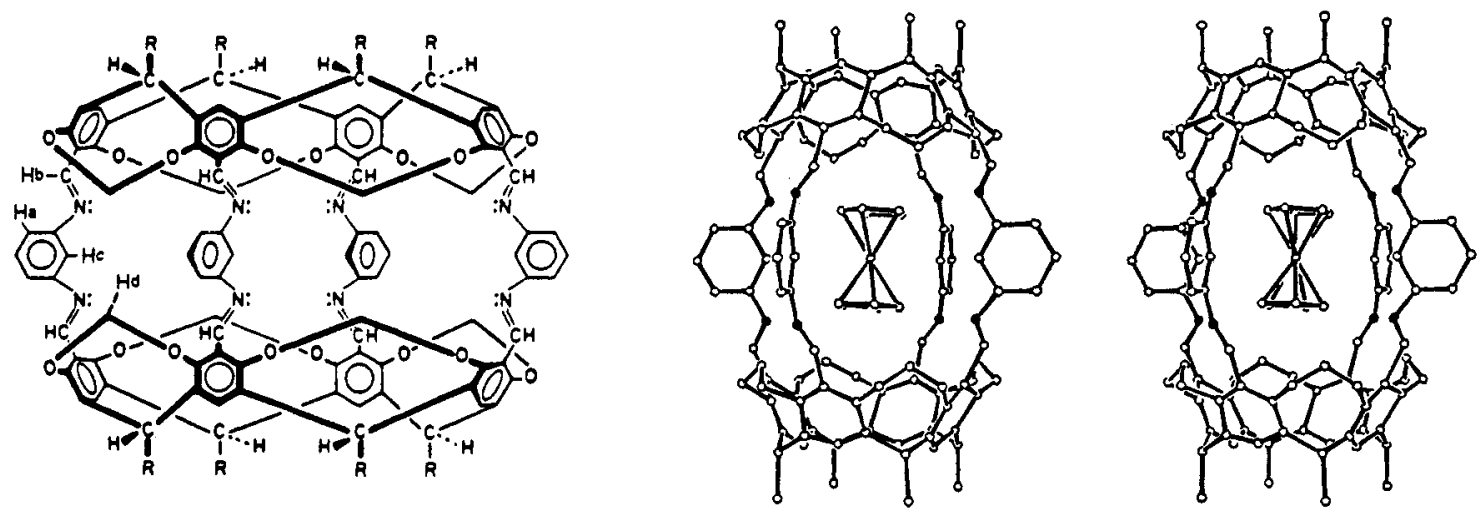

Fig. 3. A stereoview of 3 crystallized with ferrocene as guest; shown without $\mathrm{H}$ atoms, and with $-\mathrm{CH}_{3}$ groups replacing the n-pentyl 'feet'. $\mathrm{N}$ atoms in the bridges have been darkened.

At the present stage of refinement, the structure of 3 contains unresolved solvent of crystallization and many bonded distances that horrify the crystallographer. Yet the host and guest are clearly correct in major respects. Ferrocene's long axis coincides with that of the host, as was observed in solution. The molecule possesses a crystallographic center of symmetry, and the ferrocene perforce is also centrosymmetric (staggered). This is not the low-energy conformation for ferrocene (ref. 7). In solution, cyclopentadienyl rings are rotating rapidly on the NMR time scale, and indeed simple potential-energy calculations suggest that the barrier to such rotation due to non-bonded interactions with the host is only about $4-8 \mathrm{~kJ} \mathrm{~mol}^{-1}$.

The surface area of the host is reduced by $17 \AA^{2}$ by contact with ferrocene (vdW+0.2); specifically, the guest makes contact with the $\mathrm{C}$ and $\mathrm{N}$ atoms in the $-\mathrm{CH}=\mathrm{N}$ - group, methylenes of the 'bowl', and the inward-pointing bridging aryl $\mathrm{H}$ atoms. MM3 (ref 8) minimization gives a chemically reasonable host (without alteration in conformation); we plan to use this model to improve the crystal structure refinement. A space-filling model of the host shows a startlingly ferrocene-shaped cavity.

Host 3 with ferrocene is an example of constrictive binding, the prevention of escape of the guest because of the physical shape or size of the passage (ref. $6 \mathrm{c}$ ). Guest exchange is made possible by mass action and by heating $\left(80-120^{\circ} \mathrm{C}\right)$ in solutions with new guest as solvent or solute.

We note here that the host with the same 'bowls' but with four $0-\mathrm{O}-\mathrm{CH}_{2}-\mathrm{C}_{6} \mathrm{H}_{4}-\mathrm{CH}_{2}-\mathrm{O}-$ spacers (ref. 9), unlike 3, is flexible; its crystal structure shows a closed, 'wrapped' conformation, while the minimumenergy conformation (MM3) is unwrapped. The unwrapped conformation is relatively open and would allow guests to enter and exit. A different mechanism must account for guest exchange in 3 .

\section{THREE VELCRAPLEXES}

The lock-key dimers we call 'velcraplexes' derive from monomers with large rectangular surfaces. The monomers are constructed from the 'bowl' with 'feet', as in 2 and 3; however, the four methylenes on the rim of the bowl have been replaced by $o$-pyrazine or quinoxaline groups (ref. $4,6 \mathrm{a}$ ). When four aryl $\mathrm{H}$ atoms edge the rim of the bowl, the monomer is an open-topped 'vase' which strongly binds solvent molecules. If the aryl $\mathrm{H}$ atoms are replaced by $-\mathrm{CH}_{3}$, however, the pyrazines or quinoxalines flatten out into a kite-like shape. The kite monomers react readily in organic media to produce both homo- and heterodimers with a wide range of association constants (ref. 4c). 
Kite dimers have in common a monomer with four methyl groups at the rim of the bowl. Two of these methyl groups are 'up' (Fig. 4) and two are 'out'. CPK models predict, and crystal studies confirm, that the 'out' methyls and their attached dioxyaryl moieties create a complementary 'hole' for the 'up' methyls of another monomer molecule. The crystal structures of $4 \cdot 4$ (o-dimethylpyrazine 'wings', $\mathrm{MePz} \cdot \mathrm{MePz}), 5 \cdot 5$ (dichloropyrazine, $\mathrm{ClPz} \cdot \mathrm{ClPz}$ ) and 6.6 (quinoxaline, $\mathrm{HQx} \cdot \mathrm{HQx}$ ) all have the usual difficulties associated with crystals of large molecules with a high proportion of solvent. However, the dimers themselves are well enough characterized to provide correlations with phenomena observed in solution.
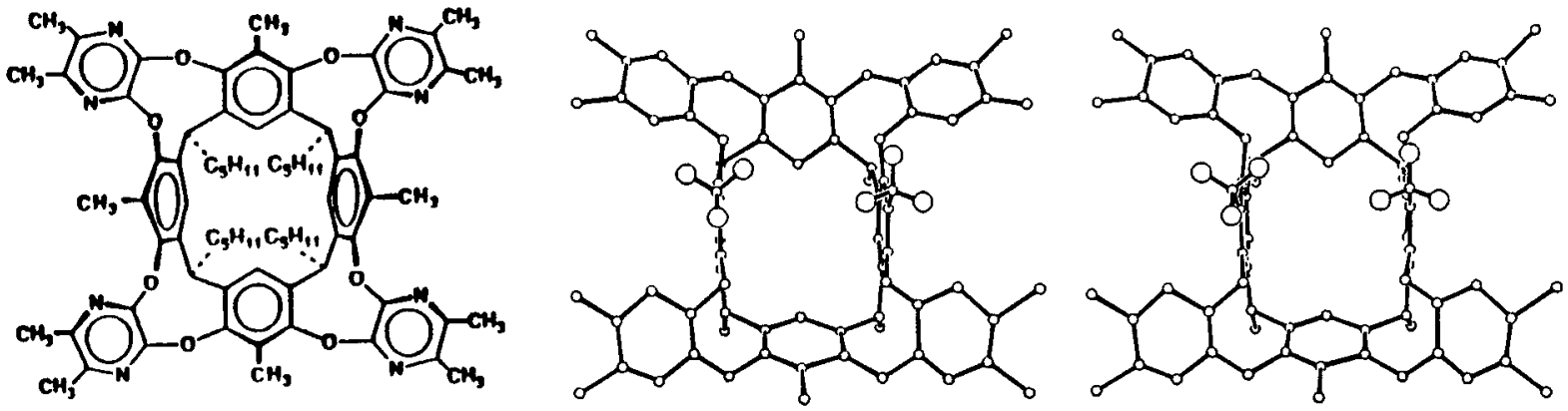

Fig. 4. Stereoview of monomer 4, with o-dimethylpyrazine 'wings'. The n-pentyl feet of the crystal structure are replaced here by methyl groups. Hydrogen atoms have been omitted, except for those of the 'up' methyls, for which the $\mathrm{H}$ atoms are shown as large circles (see text).
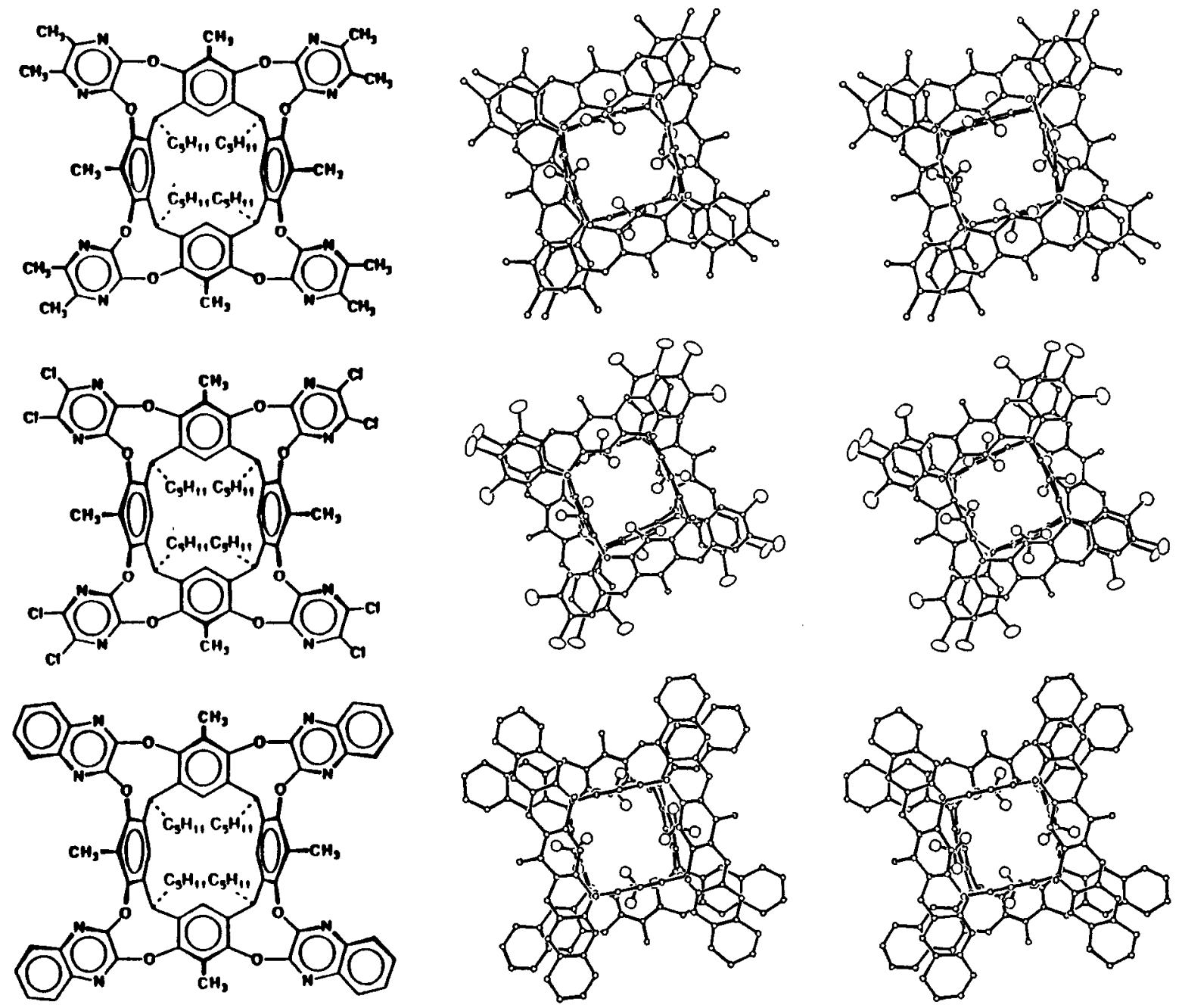

Fig. 5. Stereoviews of the velcraplexes $4 \cdot 4,5 \cdot 5$ and $6 \cdot 6$. $H$ atoms have been omitted except for the $H$ of the locking methyls (large circles). 
Thermodynamic parameters for complexation of the three homodimers discussed here are presented in Table 1. The associations of the pyrazine molecules are, surprisingly, both entropy- and enthalpy-driven, while the dimerization of the quinoxaline kite, with by far the largest $\mathrm{K}_{\mathrm{a}}$, is entropy-opposed. The atom-atom potential energies, also shown in the table, presumably should parallel $\Delta \mathrm{H}^{\circ}$. The difference between the values for $\mathrm{MePz} \cdot \mathrm{MePz}$ and $\mathrm{CIPz} \cdot \mathrm{ClPz}$ may not be significant, but is in the wrong direction; for $\mathrm{HQx} \cdot \mathrm{HQx}$, the potential energy is lower, as expected for a larger dimer with more inter-monomer contacts. We note that the most important interactions in the potential-energy summation are locking-methyl C-H...O contacts, which are essentially the same for all three dimers. These energy terms are very sensitive to structural details.

The change in free surface area upon dimerization should give indications of both $\Delta \mathrm{H}^{\circ}$ and $\Delta S^{\circ}$. With the very similar dimers $\mathrm{MePz} \cdot \mathrm{MePz}(\mathbf{4} \cdot 4)$ and $\mathrm{ClPz} \cdot \mathrm{ClPz}(5 \cdot 5)$, the trend in surface area reduction is in the same direction as $\Delta \mathrm{G}^{\circ}$. A greater reduction in free surface should mean more close contacts, and also more solvent molecules liberated, therefore stronger binding. There is no such correlation between the surface area calculation and $\Delta G^{\circ}$ when the quinoxaline dimer 6.6 is included. The fact that the surface area reduction for 6.6 is smaller than for the weaker complexes 4.4 and 5.5 may indicate that the larger dimer (Fig. 5) binds more solvent molecules. The overlap of the two monomers is less complete in 6.6 . Thus the change in free surface area parallels $\Delta S^{0}$, at least in the pyrazine and quinoxaline dimers compared here.

Table 1. Thermodynamic parameters and $\mathrm{K}_{\mathrm{a}}$ values for association of the Velcraplexes in $\mathrm{CDCl}_{3}$ at 273 $\mathrm{K}(\mathrm{ref} .4 \mathrm{c})$. Also shown: Inter-monomer non-bonded potential energy and change in monomer free surface area upon dimerization ( $\mathrm{vdW}+0.2 \AA$ ) (this work).

\begin{tabular}{l|l|l|l|l|l|l}
\hline Dimer & $\begin{array}{l}\Delta \mathrm{G}^{\circ} \\
\mathrm{kJ} \mathrm{mol}-1\end{array}$ & $\begin{array}{l}\Delta \mathrm{H}^{\circ} / \\
\mathrm{kJ} \mathrm{mol}^{-1}\end{array}$ & $\begin{array}{l}\Delta \mathrm{S}^{\circ} \\
\mathrm{J} \mathrm{mol}^{-1} \mathrm{~K}^{-1}\end{array}$ & $\begin{array}{l}\mathrm{K}_{\mathrm{a}} / \mathrm{M}^{-1} \\
(\mathrm{x} \mathrm{10}-3)\end{array}$ & $\begin{array}{l}\text { Potential } \\
\text { Energy/kJ }\end{array}$ & $\Delta$ Area/ $\AA^{2}$ \\
\hline $\mathrm{MePz} \cdot \mathrm{MePz}$ & -21.2 & -18.9 & 8.4 & 11.2 & -188 & -31 \\
\hline $\mathrm{ClPz} \cdot \mathrm{ClPz}$ & -17.0 & -15.7 & 4.6 & 1.8 & -194 & -22 \\
\hline $\mathrm{HQx} \cdot \mathrm{HQx}$ & -28.5 & -30.6 & -7.9 & 283 & -204 & -20 \\
\hline
\end{tabular}

\section{CONCLUSIONS}

CPK models, originally derived from crystal structure results, have guided the design of complexing partners with a wide range of properties. The complexes presented here associate in organic media, a process which is usually entropy-opposed; some of the 'velcraplexes', however, are entropy-driven. Unless the partners are highly preorganized for complexation, crystal structures may not reflect the molecules in solution. Molecular mechanics and atom-atom potentials help to improve the models from underdetermined crystal studies, and may also help to bridge the gap between solid-state and solution phenomena. The change in free surface area of the host (or monomer) on complexation shows promise as a measure of close contact in the complex.

\section{REFERENCES}

1. J. C. Sherman, C. B. Knobler and D. J. Cram, JAAm, Chem. Soc. 113, 2194-2204 (1991).

2. M. E.Tanner, C. B. Knobler and D. J. Cram, J.Am, Chem. Soc. 112, 1659-1660 (1990).

3. A. Gavezzotti, J.Am. Chem. Soc. 107, 962-967 (1985).

4. a. J. A. Bryant, C. B. Knobler and D. J. Cram, J.Am. Chem. Soc. 112, 1254-1255 (1990);

b. J. A. Bryant, J. L. Ericson and D.J. Cram, L.Am. Chem. Soc. 112, 1255-1256 (1990);

c. D. J. Cram, H.-J. Choi, J. A. Bryant and C. B. Knobler, J.Am. Chem, Soc. 114, 7748-7765 (1992).

5. D. J. Cram, M. E. Tanner, S. J. Keipert and C. B. Knobler, JAm. Chem. Soc. 112, 1659-1660 (1990).

6. a. D. J. Cram, Nature 356, 29-36 (1992);

b. D. J. Cram, Angew. Chem. 103, 1048-1051 (1991); Angew. Chem. Int. Ed. Engl. 30, 1024-1027 (1991).

c. M. L. C. Quan and D. J. Cram, J. Am. Chem. Soc. 113, 2754-2755 (1991).

7. E. Maverick and J. D. Dunitz, Mol. Phys. 62, 451-459 (1987).

8. a. N. L. Allinger, Y. H. Yuh and J.-H. Lii, L. Am. Chem. Soc. 111, $8551-8566$ (1989).

b. Energy minimization for the host 3 was provided by J. Storer.

9. D. J. Cram, M. T. Blanda, K. Paek and C. B. Knobler, J. Am. Chem. Soc. 114, 7765-7773 (1992). 